\title{
Relationship between history of coronary heart disease at dialysis initiation and onset of events associated with heart disease: a propensity-matched analysis of a prospective cohort study
}

Daijo Inaguma ${ }^{1,2^{*}}$, Shigehisa Koide ${ }^{1,2}$, Kazuo Takahashi $^{1}$, Hiroki Hayashi ${ }^{1}$, Midori Hasegawa ${ }^{1}$ and Yukio Yuzawa ${ }^{1}$

\begin{abstract}
Background: Chronic kidney disease (CKD) is an independent risk factor for cardiovascular disease (CVD) events, and a number of reports have shown a relationship between CKD and CVD in pre-dialysis or maintenance dialysis patients. However, few studies have reported serial observations during dialysis initiation and maintenance. Therefore, we examined whether the incidence of heart disease events differed between CKD patients with and without a history of coronary heart disease (CHD) at dialysis initiation.
\end{abstract}

Methods: The subjects were patients in the 17 centers participating in the Aichi Cohort Study of Prognosis in Patients Newly Initiated into Dialysis (AICOPP) from October 2011 to September 2013. We excluded nine patients whose outcomes were unknown, as determined by a survey conducted at the end of March 2015. Thus, we enrolled 1,515 subjects into the study. We classified patients into 2 groups according to the history of CHD (i.e., a CHD group and a non-CHD group). Propensity scores (PS) represented the probability of being assigned to a group with or without a history of CHD. Onset of heart disease events and associated mortality and all-cause mortality were compared in PSmatched patients by using the log-rank test for Kaplan-Meier curves. Factors contributing to heart disease events were examined using stepwise multivariate Cox proportional hazards analysis.

Results: There were 254 patients in each group after PS-matching. During observation, heart disease events occurred in 85 patients (33.5\%) in the CHD group and 48 (18.9\%) patients in the non-CHD group. The incidence was significantly higher in the CHD group $(p<0.0001)$. The CHD group was associated with higher incidence of heart disease events (vs. the non-CHD group, hazard ratio $=1.750,95 \%$ confidence interval $=1.160-2.639$ ). In addition, comorbidities such as diabetes mellitus, low body mass index, and low serum high-density lipoprotein cholesterol were associated with higher incidence of events.

Conclusion: History of CHD at dialysis initiation was associated with a higher incidence of heart disease events and mortality and all-cause mortality.

Trial registration: UMIN 000007096. Registered 18 January 2012.

Keywords: Chronic kidney disease, Coronary heart disease, Dialysis initiation, Cardiovascular disease, Mortality

\footnotetext{
* Correspondence: daijo@fujita-hu.ac.jp

${ }^{1}$ Department of Nephrology, Fujita Health University School of Medicine,

Toyoake, Aichi, Japan

${ }^{2}$ The Aichi Cohort Study of Prognosis in Patients Newly Initiated Into Dialysis

(AICOPP) Group, Aichi, Japan
}

\section{Biomed Central}

(c) The Author(s). 2017 Open Access This article is distributed under the terms of the Creative Commons Attribution 4.0 International License (http://creativecommons.org/licenses/by/4.0/), which permits unrestricted use, distribution, and reproduction in any medium, provided you give appropriate credit to the original author(s) and the source, provide a link to the Creative Commons license, and indicate if changes were made. The Creative Commons Public Domain Dedication waiver (http://creativecommons.org/publicdomain/zero/1.0/) applies to the data made available in this article, unless otherwise stated. 


\section{Background}

Chronic kidney disease (CKD) eventually progresses to end-stage renal disease, and is also associated with cardiovascular disease (CVD) events and mortality. CKD is an independent risk factor for CVD [1], and many reports have indicated that CKD is associated with the onset of CVD events, including coronary heart disease (CHD), heart failure, cerebrovascular disease, and death [2-7]. The Kidney Disease: Improving Global Outcomes CKD Work Group 2011 clinical practice guideline indicated that as the estimated glomerular filtration rate (eGFR) declines or urinary protein increases, the incidence of CVD-related death increases [8].

Studies have shown that hypertension, dyslipidemia, activation of the renin-angiotensin system, chronic inflammation, oxidative stress, insulin resistance, poor vitamin D status, and increase in uremic toxins such as indoxyl sulfate, asymmetric dimethylarginine, and fibroblast growth factor 23 are associated with the pathogenesis of CVD in patients with CKD [9-15]. eGFR decline may exacerbate the effects of the above-described factors. Moreover, dialysis initiation increases the risk of CVD because of intradialytic hypotension due to ultrafiltration, acidosis, or mineral metabolism disorders.

Several reports previously indicated that CVD leads to poor outcomes in limited to pre-dialysis or maintenance dialysis patients $[3,16-18]$. There are few previous studies describing the prognosis of dialysis patients whose baseline was set at the time dialysis was initiated. Therefore, we examined whether the incidence of heart disease events differed between CKD patients with and without a history of $\mathrm{CHD}$ at dialysis initiation. In this study, we defined heart disease events and mortality and all-cause mortality as outcomes. We compared the outcomes by using propensity score (PS)-matching.

\section{Methods \\ Subjects}

The subjects were patients in whom dialysis had recently been initiated at the 17 centers that participated in the Aichi Cohort Study of Prognosis in Patients Newly Initiated into Dialysis (AICOPP) between October 2011 and September 2013 [19]. Patients who were withdrawn from dialysis while hospitalized, died while hospitalized, or did not agree to be registered were excluded. The multicenter prospective study cohort included 1,524 patients who were at least 20 years old, had CKD, and provided written informed consent. We excluded 9 patients whose outcomes were unknown, as determined by a survey conducted at the end of March 2015. Thus, we enrolled 1,515 subjects in the study. The dataset analyzed in the present study is presented in the Additional file 1.

\section{Patient characteristics and data at the time dialysis was} initiated (baseline)

The baseline was defined as the time at which dialysis was initiated. Body mass index (BMI) was measured at the first dialysis session. Diabetes was defined as a fasting blood glucose level $\geq 126 \mathrm{mg} / \mathrm{dL}$, random blood glucose level $\geq 200 \mathrm{mg} / \mathrm{dL}, \mathrm{HbA} 1 \mathrm{c}$ (National Glycohemoglobin Standardization Program) level $\geq$ $6.5 \%$, use of insulin, or use of oral hypoglycemic agents. Medication use referred to the drugs taken at the time of dialysis initiation. Tests were performed using blood samples taken before the first dialysis session. Blood pressure was also measured before the first dialysis session. The following were considered to be heart failure symptoms and findings: (1) dyspnea

Table 1 Baseline characteristics of all patients

\begin{tabular}{lllr}
\hline Characteristics $n$ (1,515) & $\begin{array}{l}\text { CHD group } \\
n(256)\end{array}$ & $\begin{array}{l}\text { no CHD group } \\
n(1,259)\end{array}$ & $p$ value \\
\hline Age, yrs & $72.7 \pm 10.0$ & $66.4 \pm 13.4$ & $<0.001$ \\
Female, \% & 22.3 & 34.4 & $<0.001$ \\
Diabetes mellitus, \% & 64.8 & 48.2 & $<0.001$ \\
BMl, kg/m ${ }^{2}$ & $23.0 \pm 3.5$ & $23.6 \pm 4.5$ & 0.062 \\
SBP, mmHg & $143 \pm 26$ & $153 \pm 26$ & $<0.001$ \\
DBP, mmHg & $72 \pm 14$ & $78 \pm 15$ & $<0.001$ \\
eGFR, ml/min/1.73 m ${ }^{2}$ & $6.4 \pm 3.1$ & $5.2 \pm 1.9$ & $<0.001$ \\
Creatinine, mg/dL & $7.84 \pm 2.51$ & $9.21 \pm 3.30$ & $<0.001$ \\
BUN, mg/dL & $88.3 \pm 28.9$ & $92.4 \pm 30.7$ & 0.048 \\
Hemoglobin, g/dL & $9.4 \pm 1.4$ & $9.4 \pm 1.6$ & 0.909 \\
Albumin, g/dL & $3.15 \pm 0.58$ & $3.21 \pm 0.60$ & 0.111 \\
Uric acid, mg/dL & $8.8 \pm 2.7$ & $8.8 \pm 2.3$ & 0.894 \\
Potassium, mEq/L & $4.5 \pm 0.8$ & $4.6 \pm 0.8$ & 0.271 \\
Adjusted calcium, mg/dL & $8.8 \pm 0.9$ & $8.6 \pm 1.1$ & 0.023 \\
Phosphorus, mg/dL & $5.8 \pm 1.5$ & $6.5 \pm 1.9$ & $<0.001$ \\
LDL-cholesterol, mg/dL & $83 \pm 32$ & $91 \pm 35$ & 0.002 \\
HDL-cholesterol, mg/dL & $41 \pm 14$ & $45 \pm 17$ & $<0.001$ \\
Triglyceride, mg/dL & $125 \pm 95$ & $125 \pm 64$ & 0.959 \\
CRP, mg/dL & $2.0 \pm 3.3$ & $1.8 \pm 4.3$ & 0.532 \\
Use of ARBs or ACEls, \% & 61.7 & 60.1 & 0.674 \\
Use of $\beta$-blockers, \% & 56.3 & 30.2 & $<0.001$ \\
Use of anti-platelet agents, \% & 73.8 & 21.4 & $<0.001$ \\
Use of warfarin, \% & 12.9 & 5.8 & $<0.001$ \\
Use of loop diuretics, \% & 77.3 & 63.3 & $<0.001$ \\
Use of statins, \% & 66.4 & 34.8 & \\
Use of ESAs, \% & 84.8 & 86.1 & \\
\hline Mean \pm Standand de & & \\
\hline
\end{tabular}

Mean \pm Standard deviation

CHD coronary heart disease, $B M I$ body mass index, $S B P$ systolic blood pressure, $D B P$ diastolic blood pressure, eGFR estimated glomerular filtration rate, $B U N$ blood urea nitrogen, $L D L$ low density lipoprotein, $H D L$ high density lipoprotein, CRP C-reactive protein, ARBs angiotensin receptor blockers, ESAs erythropoiesis stimulating agents 
or orthopnea with hypoxemia; (2) pulmonary congestion or pleural effusion seen on plain chest radiography; and (3) physical findings related to volume excess, such as edema, weight gain, or jugular venous distension.

\section{Definition of coronary heart disease}

We classified patients into 2 groups by history of CHD (i.e., a CHD group and a non-CHD group. A diagnosis of CHD was based on information taken from the medical records. History of CHD was defined as a history of percutaneous coronary artery intervention (PCI) or coronary artery bypass graft $(\mathrm{CABG})$, ischemic change seen on electrocardiogram with symptoms including chest pain on exertion, or positive findings on stress myocardial scintigraphy.

\section{Survey of events associated with heart disease and survival prognosis}

Events associated with heart disease and survival prognosis as of March 31, 2015 were determined by surveying medical records. For patients who were transferred to other institutions, information was obtained by mailing out survey forms.

\section{Outcomes}

The study outcomes included: (1) heart disease events, including onset of acute coronary syndrome, PCI, CABG, hospitalization due to heart failure, or cardiogenic sudden death; (2) mortality due to heart disease; and (3) all-cause mortality.

\section{Statistical processing}

The Easy $\mathrm{R}$ program was used for statistical processing [20]. Patient characteristics and baseline data were compared for the two groups using the t-test for continuous variables and Fisher's exact test for nominal variables. Heart disease events and mortality and allcause mortality were compared using the log-rank test for Kaplan-Meier curves for the two groups. The PS, which we calculated using logistic regression models, represented the probability that a patient would be assigned to a group with or without a history of CHD. Using a PS-matching procedure, the 2 groups were similarly distributed, indicating that the differences in covariates between the groups were minimized. Moreover, heart disease events and mortality and all-cause mortality were compared for PSmatched patients. Factors contributing to the onset of heart disease events were examined using univariate Cox proportional hazards regression analysis. In addition to a history of CHD, age, gender, and factors that were significant in the univariate analysis (i.e., diabetes mellitus [DM], BMI, eGFR, serum creatinine, high-density lipoprotein [HDL] cholesterol, and use of $\beta$-blockers, antiplatelet agents, or statins) served as explanatory variables for the stepwise multivariate Cox proportional hazards analysis. Continuous variables were expressed as the mean and standard deviation, and categorical variables were presented as percentages. $P$-values less than $5 \%$ were considered statistically significant.

\section{Results}

Comparison of patient characteristics and baseline data

Table 1 shows the patient characteristics and baseline data for the 2 groups. Notably, the CHD group had significantly older patients; a lower percentage of females; a higher prevalence of DM; lower blood pressure, eGFR,

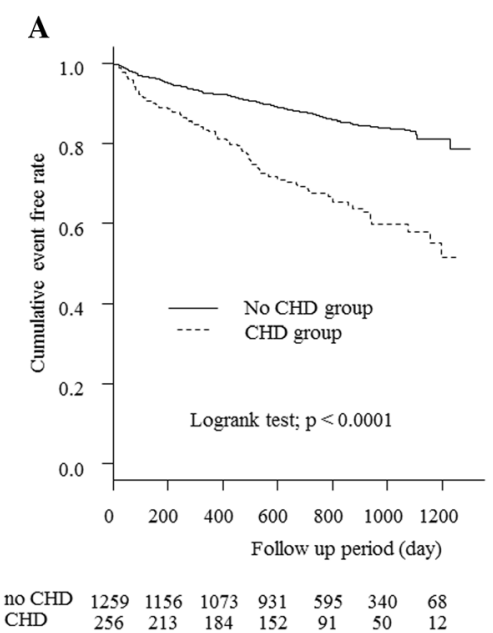

B

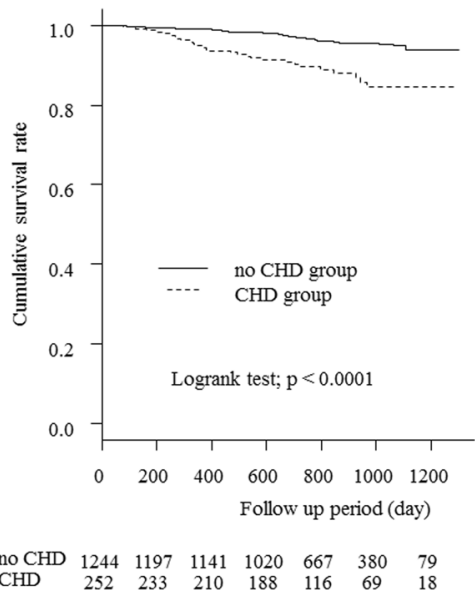

Fig. 1 a Comparison of events from heart disease between the 2 groups before PS matching. Significant differences were observed between the 2 groups' cumulative event free rates $(p<0.0001)$. b Comparison of death from heart disease between the 2 groups before PS matching. Significant differences were observed between the 2 groups' cumulative survival rates $(p<0.0001)$. CHD; coronary heart disease, PS; propensity score 
and serum phosphorus and cholesterol levels; and higher serum creatinine and adjusted calcium levels. The CHD group also had higher usage rates of $\beta$-blockers, antiplatelet agents, loop diuretics, and statins. Thirty-seven patients underwent both PCI and CABG, 113 underwent only PCI, and 28 underwent only CABG.

\section{Comparison of heart disease events and mortality}

Figure 1 displays the Kaplan-Meier curves for the 2 groups in terms of heart disease events and mortality. During observation, heart disease events occurred in 87 patients (34.0\%) in the CHD group and 180 (14.3\%) in the non-CHD group. The incidence was significantly higher in the CHD group $(p<0.0001)$. Death due to heart disease occurred in 28 patients (10.9\%) in the CHD group and 49 (3.9\%) in the non-CHD group.

\section{PS-matched cohort}

We performed logistic regression analysis using age, gender, comorbidities such as DM, systolic blood pressure, eGFR, and use of $\beta$-blockers and statins to obtain the PS for patients with or without a history of CHD. There were 254 patients in each group. Table 2 shows the patient characteristics and baseline data in the 2 groups after PS-matching. There were no significant differences in variables except for serum HDL cholesterol levels and frequency of antiplatelet agent usage. Table 3 compares the vital signs and cardiac markers at the first dialysis session after PS-matching in the two groups. The CHD group had a significantly higher left ventricular ejection fraction on echocardiography, and higher serum brain natriuretic peptide level.

\section{Comparison of heart disease events in the two groups after PS-matching}

Figure 2 displays the Kaplan-Meier curves for the 2 groups after PS-matching, in terms of heart disease events. During observation, heart disease events occurred in 85 patients (33.5\%) in the CHD group and 48 (18.9\%) in the non-CHD group. The incidence was significantly higher in the CHD group $(p<0.0001)$.

\section{Comparison of the heart disease-related and all-cause mortality between the two groups after PS-matching}

Figure 3 displays the Kaplan-Meier curves for the 2 groups after PS-matching, in terms of heart diseaserelated and all-cause mortality. During observation, heart disease-related death occurred in 27 patients (18.9\%) in the CHD group and $12(10.6 \%)$ in the nonCHD group. The incidence was significantly higher in the CHD group $(p=0.014)$. All-cause death occurred in 70 patients $(27.6 \%)$ in the CHD group and $47(18.5 \%)$ in the non-CHD group.
Table 2 Baseline characteristics after PS matching

\begin{tabular}{|c|c|c|c|}
\hline Characteristics $n$ (508) & $\begin{array}{l}\text { CHD group } \\
n(254)\end{array}$ & $\begin{array}{l}\text { no CHD group } \\
n(254)\end{array}$ & $p$ value \\
\hline Age, yrs & $72.7 \pm 9.9$ & $73.2 \pm 9.3$ & 0.591 \\
\hline Female, \% & 22.4 & 26.0 & 0.406 \\
\hline Diabetes mellitus, $\%$ & 64.6 & 63.0 & 0.712 \\
\hline $\mathrm{BMI}, \mathrm{kg} / \mathrm{m}^{2}$ & $23.0 \pm 3.5$ & $23.3 \pm 4.0$ & 0.485 \\
\hline $\mathrm{eGFR}, \mathrm{ml} / \mathrm{min} / 1.73 \mathrm{~m}^{2}$ & $6.4 \pm 3.1$ & $6.0 \pm 2.5$ & 0.062 \\
\hline Creatinine, mg/dL & $7.85 \pm 2.51$ & $8.09 \pm 2.45$ & 0.260 \\
\hline $\mathrm{BUN}, \mathrm{mg} / \mathrm{dL}$ & $88.2 \pm 29.0$ & $88.7 \pm 29.1$ & 0.862 \\
\hline Hemoglobin, g/dL & $9.4 \pm 1.4$ & $9.3 \pm 1.5$ & 0.355 \\
\hline Albumin, $\mathrm{g} / \mathrm{dL}$ & $3.14 \pm 0.58$ & $3.16 \pm 0.56$ & 0.738 \\
\hline Uric acid, mg/dL & $8.8 \pm 2.7$ & $8.5 \pm 2.4$ & 0.146 \\
\hline Potassium, mEq/L & $4.5 \pm 0.8$ & $4.6 \pm 0.9$ & 0.238 \\
\hline Adjusted calcium, mg/dL & $8.7 \pm 0.9$ & $8.6 \pm 1.0$ & 0.193 \\
\hline Phosphorus, mg/dL & $5.7 \pm 1.5$ & $6.0 \pm 1.7$ & 0.050 \\
\hline LDL-cholesterol, mg/dL & $83 \pm 32$ & $83 \pm 33$ & 0.992 \\
\hline HDL-cholesterol, mg/dL & $41 \pm 14$ & $46 \pm 17$ & 0.003 \\
\hline Triglyceride, mg/dL & $125 \pm 96$ & $111 \pm 46$ & 0.059 \\
\hline CRP, mg/dL & $2.0 \pm 3.3$ & $2.0 \pm 4.4$ & 0.946 \\
\hline Use of ARBs or ACEls, \% & 61.8 & 60.2 & 0.785 \\
\hline Use of $\beta$-blockers, $\%$ & 55.9 & 48.4 & 0.109 \\
\hline Use of anti-platelet agents, \% & 74.0 & 28.7 & $<0.001$ \\
\hline Use of warfarin, \% & 13.0 & 11.0 & 0.586 \\
\hline Use of loop diuretics, \% & 77.2 & 74.0 & 0.408 \\
\hline Use of statins, \% & 66.1 & 63.8 & 0.642 \\
\hline Use of ESAs & 84.6 & 87.8 & 0.235 \\
\hline
\end{tabular}

Mean \pm Standard deviation

$P S$ propensity score, $C H D$ coronary heart disease, $B M I$ body mass index, eGFR estimated glomerular filtration rate, $B U N$ blood urea nitrogen, $L D L$ low density lipoprotein, $H D L$ high density lipoprotein, CRP C-reactive protein, ARBs angiotensin receptor blockers

Table 3 The comparison of vital signs and cardiac markers at first dialysis session between 2 groups

\begin{tabular}{lllr}
\hline $\begin{array}{l}\text { Characteristics } \\
n(508)\end{array}$ & $\begin{array}{l}\text { CHD group } \\
n(254)\end{array}$ & $\begin{array}{l}\text { no CHD group } \\
n(254)\end{array}$ & $p$ value \\
\hline SBP, mmHg & $143 \pm 26$ & $145 \pm 25$ & 0.462 \\
DBP, mmHg & $72 \pm 14$ & $72 \pm 15$ & 0.579 \\
HR,/min & $77 \pm 15$ & $76 \pm 16$ & 0.778 \\
Heart failure & 46.5 & 37.8 & 0.072 \\
symptom, \% & & & \\
CTR, \% & $56.6 \pm 6.4$ & $56.1 \pm 7.1$ & 0.433 \\
LVEF, \% & $52.9 \pm 15.1$ & $62.2 \pm 12.0$ & $<0.001$ \\
BNP, pg/mL & $566(247,1345)^{\text {a }}$ & $253(105,614)^{\text {a }}$ & $<0.001$ \\
UFV at 1st dialysis & $1,014 \pm 960$ & $938 \pm 829$ & 0.350 \\
session, mL & & &
\end{tabular}

${ }^{a}$ Median (inter-quartile range)

$S B P$ systolic blood pressure, DBP diastolic blood pressure, $H R$ heart rate, CTR cardiothoracic ratio, $L V E F$ left ventricular ejection fraction, $B N P$ brain natriuretic peptide, UFV ultrafiltration volume 


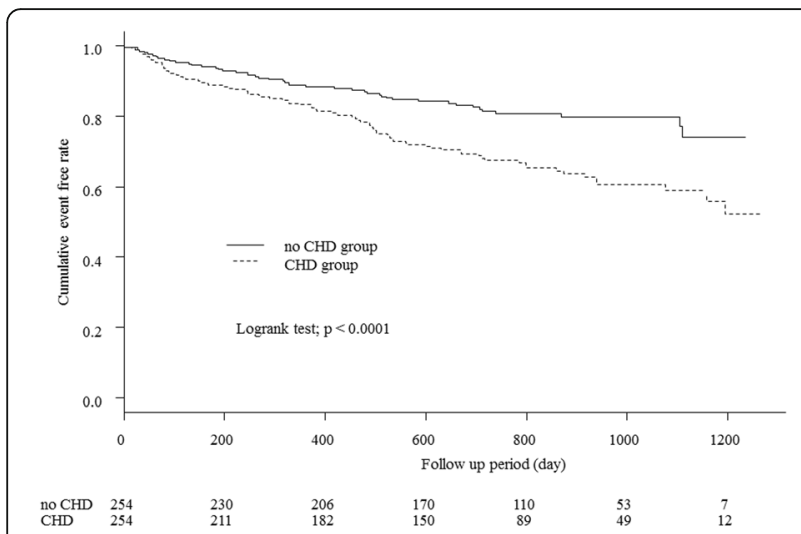

Fig. 2 Comparison of death from heart disease between the 2 groups after PS matching. Significant differences were observed between the 2 groups' cumulative event free rates $(p<0.0001)$. CHD; coronary heart disease, PS; propensity score

\section{Factors affecting heart disease events among patients after PS-matching}

Table 4 shows the results of univariate analysis of heart disease events as a response variable. The rate of heart disease events was significantly higher in the CHD group (CHD group vs. non-CHD group: hazard ratio $[\mathrm{HR}]=1.955,95 \%$ confidence interval $[\mathrm{CI}]=1.369-2.793, p<0.001$ ). In addition, heart disease events were associated with comorbidities such as DM; low BMI; low systolic blood pressure; high eGFR; low serum creatinine; low serum HDL cholesterol; and use of $\beta$-blockers, antiplatelet agents, or statins. The results of the stepwise multivariate Cox proportional hazards analysis are shown in Fig. 4. The CHD group had a higher incidence of events associated with heart disease (vs. the non-CHD group, $\mathrm{HR}=1.750,95 \% \mathrm{CI}=1.160-$ 2.639, $p=0.008)$. In addition, DM, low BMI, and low serum HDL cholesterol level were associated with a higher incidence of these events.

\section{Discussion}

In this study, we enrolled patients in whom dialysis was initiated and who were followed thereafter. We confirmed that a history of CHD at the initiation of dialysis was associated with a higher incidence of heart disease events and mortality during dialysis. In addition, the same results were obtained when using PS-matching. We surmised that myocardial remodeling had occurred in these patients. Therefore, disturbed cardiac function can be exacerbated by dialysis initiation, and many factors can arise from dialysis therapy, such as intra-dialysis hypotension due to ultrafiltration. In accordance with the considerations above, the CHD group had poorer prognosis.

We compared the outcomes of the 2 groups using PSmatching. The CHD group had a significantly older age, lower percentage of females, and higher prevalence of DM. The patients in the CHD group were likely to develop these associated events and die of heart disease. Therefore, we used PS-matching to adjust for variables. We confirmed that there was a relationship between history of CHD and outcomes after PS-matching. However, there was no significant difference in the prevalence of heart failure symptoms at dialysis initiation between the 2 groups. We assumed that patients in both groups began dialysis under similar conditions, and that that chronically disturbed cardiac function led to poor outcomes.

Reports of evaluation using the Charlson score for the association between complications or comorbidity before introduction of dialysis, and prognosis after dialysis introduction, have been published sporadically [21-23]. Wu et al. [23] reported the association of a high Charlson
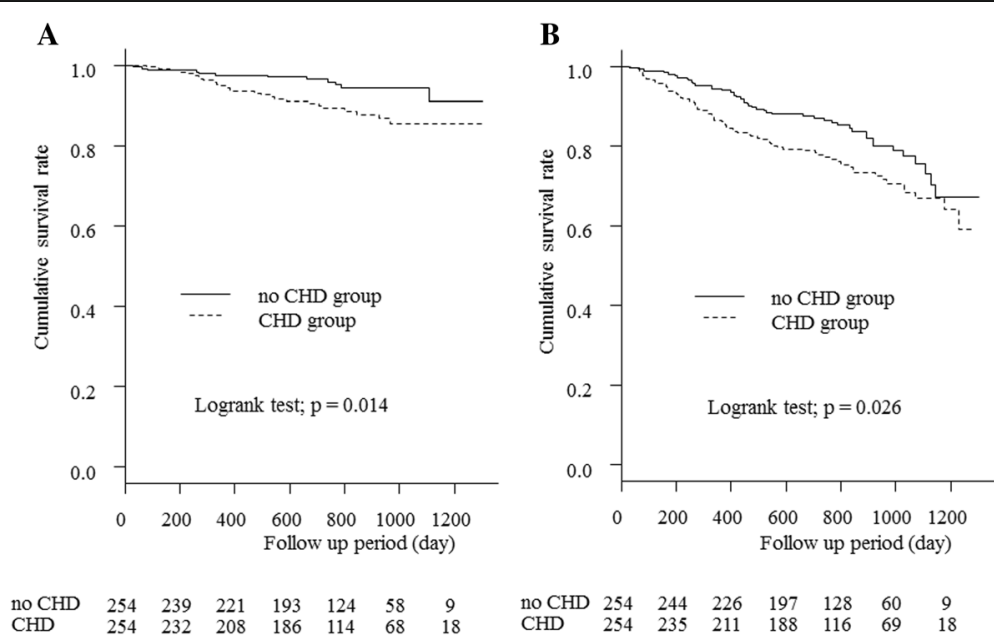

Fig. 3 a Comparison of death from heart disease between the 2 groups after PS matching. Significant differences were observed between the 2 groups' cumulative survival rates $(p=0.014)$. $\mathbf{b}$ Comparison of all-cause death from heart disease between the 2 groups after PS matching. Significant differences were observed between the 2 groups' cumulative survival rates $(p=0.026)$. CHD; coronary heart disease, PS; propensity score 
Table 4 Hazard ratio (HR) for cardiac disease related events using a univariate Cox proportional analysis in the propensity score-matched cohort

\begin{tabular}{|c|c|c|c|}
\hline Variables & $\mathrm{HR}$ & $95 \% \mathrm{Cl}$ & $P$ value \\
\hline CHD group (vs. no CHD group) & 1.955 & $1.369-2.793$ & $<0.001$ \\
\hline Age (/10 year) & 1.065 & $0.884-1.283$ & 0.506 \\
\hline Female gender & 0.866 & $0.574-1.308$ & 0.494 \\
\hline Diabetes Mellitus & 1.781 & $1.201-2.641$ & 0.004 \\
\hline BMI & 0.949 & $0.903-0.997$ & 0.036 \\
\hline $\mathrm{SBP}(/ 10 \mathrm{mmHg})$ & 0.928 & $0.867-0.993$ & 0.030 \\
\hline DBP (/10 mmHg) & 0.897 & $0.796-1.012$ & 0.078 \\
\hline eGFR & 1.053 & $1.005-1.104$ & 0.030 \\
\hline Creatinine & 0.924 & $0.860-0.993$ & 0.032 \\
\hline BUN & 0.997 & $0.991-1.003$ & 0.365 \\
\hline Hemoglobin & 1.080 & $0.962-1.212$ & 0.193 \\
\hline Albumin & 0.976 & $0.726-1.313$ & 0.874 \\
\hline Uric acid & 1.011 & $0.944-1.082$ & 0.756 \\
\hline Potassium & 0.971 & $0.793-1.189$ & 0.776 \\
\hline Adjusted calcium & 1.113 & $0.922-1.343$ & 0.265 \\
\hline Phosphorus & 0.899 & $0.805-1.004$ & 0.059 \\
\hline LDL-cholesterol (/10 mg/dL) & 0.954 & $0.897-1.014$ & 0.129 \\
\hline HDL-cholesterol (/10 mg/dL) & 0.841 & $0.735-0.961$ & 0.011 \\
\hline Triglyceride & 0.999 & $0.997-1.002$ & 0.669 \\
\hline CRP & 1.022 & $0.981-1.065$ & 0.292 \\
\hline Use of ARBs or ACEls & 0.895 & $0.632-1.268$ & 0.532 \\
\hline Use of $\beta$-blockers & 1.465 & $1.034-2.075$ & 0.032 \\
\hline Use of anti-platelet agents & 1.920 & $1.344-2.743$ & $<0.001$ \\
\hline Use of loop diuretics & 1.226 & $0.808-1.861$ & 0.339 \\
\hline Use of statins & 1.756 & $1.183-2.605$ & 0.005 \\
\hline
\end{tabular}

$H R$ hazard ratio, $\mathrm{Cl}$ confidence interval, $C H D$ coronary heart disease, $B M I$ body mass index, SBP systolic blood pressure, DBP diastolic blood pressure, eGFR estimated glomerular filtration rate, $B U N$ blood urea nitrogen, $L D L$ low density lipoprotein, $H D L$ high density lipoprotein, $C R P C$-reactive protein, $A R B$ s angiotensin receptor blockers

comorbidity index with elevated risk of death among nearly 80,000 patients in Taiwan in whom dialysis was initiated. Ivory et al. [24] scored complications and analyzed the relationship of this score to prognosis in more than 2,000 patients in Australia and New Zealand who began dialysis. In their study, the prevalence of $\mathrm{CHD}$ as a complication was $39 \%$ in the surviving group and $64 \%$ in the non-surviving group, which are higher than the rates observed in our study. In the analysis of prognosis, the survival rate at 6 months after dialysis introduction was significantly poorer in the CHD-complicated group ( $\mathrm{HR}=1.72$; $95 \% \mathrm{CI}=1.51-$ 1.96), similar to our findings. Among the reports of studies confined to CHD, Genesh et al. [25] compared the prognosis in the group receiving hemodialysis treatment with that in the group treated with peritoneal dialysis. They demonstrated that the prognosis after dialysis introduction was

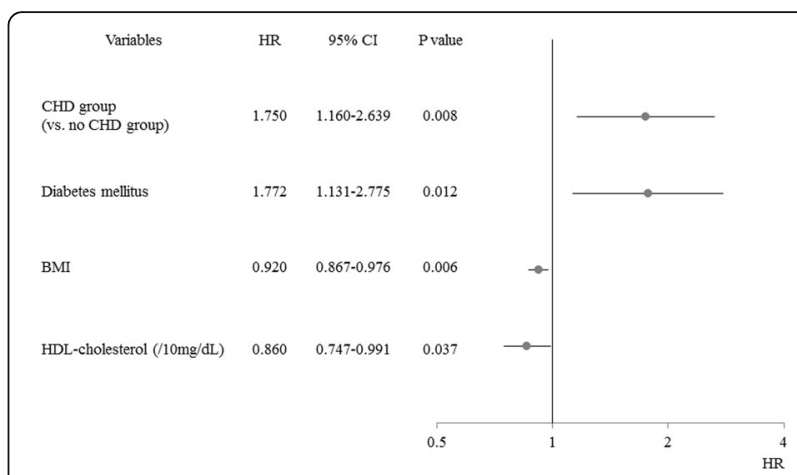

Fig. 4 The risk factors for events from heart disease by multivariate Cox proportional hazard analysis using the stepwise method between the 2 groups after PS matching. The CHD group was associated with poorer outcome ( $\mathrm{HR}=1.750,95 \% \mathrm{Cl}=1.160-2.639, p=0.008)$. CHD; coronary heart disease, BMl; body mass index, HDL; high density lipoprotein, PS; propensity score, PS; propensity score

poor in patients with a history of CHD, similar to the finding in our study. Patients with a history of CHD accounted for $25.9 \%$ of all patients in their study. In our study, the percentage of patients with a history of CHD was only $16.9 \%$, although the mean age was higher in our study than in their study. One factor probably explaining this difference is an ethnic difference. That is, all patients in our study were Japanese, while the percentage of Asians was only $3.7 \%$ in the study by Genesh et al. Our study can be characterized by enrollment of only Japanese (i.e., Asian) patients. It is additionally characterized, in comparison to the abovecited studies, by homogeneity of patient background variables (achieved by PS-matching), despite the small sample size. Moreover, in contrast with the above-cited studies in which total deaths were analyzed as the outcome measure, the present study also investigated heart disease events and heart disease-associated death. The results of this study may therefore contain useful information.

A guideline for secondary prevention of myocardial infarction (JCS 2011) recommends the use of antiplatelet agents and statins in patients with CHD [26]. In this study, the usage rates of antiplatelet agents and statins were 73.8 and $66.4 \%$, respectively. We considered that it is difficult to administer antiplatelet agents in some patients with CKD who have a tendency to bleed. On the other hand, administration of statins might have been interrupted because the serum low-density lipoprotein cholesterol levels decreased below the normal range in some patients. This study showed that the CHD group had lower HDL cholesterol levels, even after PSmatching. In addition, a low serum HDL cholesterol level was associated with a higher incidence of heart disease events. Comprehensive management of hypertension, renal anemia, mineral and bone disorders, and dyslipidemia in early stages of CKD before CHD onset could lead to better prognosis. Therefore, more intensive 
collaboration between nephrologists and cardiologists will be necessary.

The present study has the following limitations. First, we could question the diagnosis of CHD. Although it has the highest reliability for diagnosis, coronary angiography was not used in all patients in the CHD group. Moreover, there are reports describing coronary artery stenosis in asymptomatic patients in whom dialysis was initiated. The results revealed that over $50 \%$ of patients had over $75 \%$ coronary artery stenosis $[27,28]$. Hence, we surmised that there might have been patients in the non-CHD group who had CHD. Acute coronary syndrome or increased severity of CHD due to an increased number of stenotic or occluded coronary arteries is associated with mortality. Second, we could not evaluate the severity of CHD. In addition, the intervals between the onset of $\mathrm{CHD}$ and dialysis initiation were inconsistent.

\section{Conclusion}

A history of CHD at the time of dialysis initiation was associated with higher incidence of heart disease events and mortality and all-cause mortality. This observation indicates that CKD patients with CHD should be evaluated more thoroughly.

\section{Additional file}

Additional file 1: The dataset included the patient profiles,

comorbidities, medications, and laboratory data at dialysis initiation. (XLSX $202 \mathrm{~kb})$

\begin{abstract}
Abbreviations
AICOPP: Aichi Cohort Study of Prognosis in Patients Newly Initiated into Dialysis; BMI: Body mass index; CABG: Coronary artery bypass graft; CHD: Coronary heart disease; Cl: Confidence interval; CKD: Chronic kidney disease; CVD: Cardiovascular disease; DM: Diabetes mellitus; eGFR: Estimated glomerular filtration rate; HDL: High density lipoprotein; HR: Hazard ration; PCl: Percutaneous coronary artery intervention; PS: Propensity score
\end{abstract}

\section{Acknowledgments}

We acknowledge the support provided by the following investigators and members of the Aichi Cohort study of Prognosis in Patients Newly Initiated Into Dialysis (AICOPP), who participated in this study: Akihito Tanaka, Minako Murata, Hibiki Shinjo, Yasuhiro Otsuka, Asami Takeda (Japanese Red Cross Nagoya Daini Hospital), Hirofumi Tamai (Anjo Kosei Hospital), Tomohiko Naruse (Kasugai Municipal Hospital), Kei Kurata (Tosei General Hospital), Hideto Oishi (Komaki City Hospital), Isao Aoyama (Japanese Community Healthcare Organization Chukyo Hospital), Hiroshi Ogawa (Shinseikai Daiichi Hospital), Hiroko Kushimoto (Chita City Hospital), Hideaki Shimizu (ChubuRosai Hospital), Junichiro Yamamoto(Tsushima City Hospital), Hisashi Kurata (Toyota Kosei Hospital), Taishi Yamakawa (Toyohashi Municipal Hospital), Takaaki Yaomura (Nagoya Medical Center), Hirotake Kasuga(Nagoya Kyouritsu Hospital), Shizunori Ichida (Japanese Red Cross Nagoya Daiichi Hospital), Shoichi Maruyama (Nagoya University Graduate School of Medicine), Seiichi Matsuo (Nagoya University Graduate School of Medicine), Noritoshi Kato (Nagoya University Graduate School of Medicine).

\section{Funding}

Not applicable.
Availability of data and materials

The dataset analyzed in the present study is presented in the additional file and available.

\section{Competing interests}

The authors declare that they have no competing interests.

\section{Authors' contributions}

$\mathrm{DI}$ participated in the design of the study and interpretation of data. DI and SK surveyed and collected information about prognosis. $\mathrm{KT}$ and $\mathrm{HH}$ performed statistical analyses. DI drafted the manuscript and $\mathrm{MH}$ and $\mathrm{YY}$ revised it critically for important intellectual content. All authors read and approved the final manuscript.

\section{Consent for publication}

Not applicable.

\section{Ethics approval and consent to participate}

This study was conducted by following Ethical guidelines for Clinical Research by the Japanese Ministry of Health, Labor, and Welfare (created July 30, 2003; full revision December 28, 2004; full revision July 31, 2008) and the Helsinki Declaration (revised 2013) and was approved by the clinical research ethics committees at each AICOPP group facility (Japanese Red Cross Nagoya Daini Hospital: the approval number: 20110823-3, Anjo Kosei Hospital, Kasugai Municipal Hospital, Tosei General Hospital, Komaki City Hospital, Japanese Community Healthcare Organization Chukyo Hospital, Shinseikai Daiichi Hospital, Chita City Hospital, Chubu-Rosai Hospital, Tsushima City Hospital, Toyota Kosei Hospital, Toyohashi Municipal Hospital, Nagoya Medical Center, Nagoya Kyouritsu Hospital, Japanese Red Cross Nagoya Daiichi Hospital, Nagoya University Graduate School of Medicine, Fujita Health University School of Medicine). The subjects received oral and written explanations of the purpose of the study and provided their consent in writing.

Received: 26 August 2016 Accepted: 23 February 2017

Published online: 28 February 2017

References

1. Sarnak MJ, Levey AS, Schoolwerth AC, Coresh J, Culleton B, Hamm LL, McCullough PA, Kasiske BL, Kelepouris E, Klag MJ, Parfrey P, Pfeffer M, Raij L, Spinosa DJ, Wilson PW, American Heart Association Councils on Kidney in Cardiovascular Disease, High Blood Pressure Research, Clinical Cardiology, and Epidemiology and Prevention. Kidney disease as a risk factor for development of cardiovascular disease: a statement from the American Heart Association Councils on Kidney in Cardiovascular Disease, High Blood Pressure Research, Clinical Cardiology, and Epidemiology and Prevention. Circulation. 2003;108(17):2154-69.

2. Keith DS, Nichols GA, Gullion CM, Brown JB, Smith DH. Longitudinal followup and outcomes among a population with chronic kidney disease in a large managed care organization. Arch Intern Med. 2004;164(6):659-63.

3. Go AS, Chertow GM, Fan D, McCulloch CE, Hsu CY. Chronic kidney disease and the risks of death, cardiovascular events, and hospitalization. N Engl J Med. 2004;351(13):1296-305.

4. Kottgen A, Russell SD, Loehr LR, Crainiceanu CM, Rosamond WD, Chang PP, Chambless LE, Coresh J. Reduced kidney function as a risk factor for incident heart failure: the atherosclerosis risk in communities (ARIC) study. J Am Soc Nephrol. 2007:18(4):1307-15.

5. Anavekar NS, McMurray JJ, Velazquez EJ, Solomon SD, Kober L, Rouleau JL, White HD, Nordlander R, Maggioni A, Dickstein K, Zelenkofske S, Leimberger JD, Califf RM, Pfeffer MA. Relation between renal dysfunction and cardiovascular outcomes after myocardial infarction. N Engl J Med. 2004; 351(13):1285-95.

6. Nakayama M, Metoki H, Terawaki H, Ohkubo T, Kikuya M, Sato T, Nakayama K, Asayama K, Inoue R, Hashimoto J, Totsune K, Hoshi H, Ito S, Imai Y. Kidney dysfunction as a risk factor for first symptomatic stroke events in a general Japanese population-the Ohasama study. Nephrol Dial Transplant. 2007;22(7):1910-5

7. Ovbiagele B. Chronic kidney disease and risk of death during hospitalization for stroke. J Neurol Sci. 2011;301(1-2):46-50.

8. Levey AS, de Jong PE, Coresh J, El Nahas M, Astor BC, Matsushita K, Gansevoort RT, Kasiske BL, Eckardt KU. The definition, classification, and 
prognosis of chronic kidney disease: a KDIGO Controversies Conference report. Kidney Int. 2011;80(1):17-28.

9. de Galan BE, Perkovic V, Ninomiya T, Pillai A, Patel A, Cass A, Neal B, Poulter N, Harrap S, Mogensen CE, Cooper M, Marre M, Williams B, Hamet P, Mancia G, Woodward M, Glasziou P, Grobbee DE, MacMahon S, Chalmers J, ADVANCE Collaborative Group. Lowering blood pressure reduces renal events in type 2 diabetes. J Am Soc Nephrol. 2009;20(4):883-92.

10. Reiss AB, Voloshyna I, De Leon J, Miyawaki N, Mattana J. Cholesterol Metabolism in CKD. Am J Kidney Dis. 2015;66(6):1071-82.

11. Edner $M$, Benson L, Dahlström U, Lund LH. Association between reninangiotensin system antagonist use and mortality in heart failure with severe renal insufficiency: a prospective propensity score-matched cohort study. Eur Heart J. 2015;36(34):2318-26.

12. Onuigbo MA. RAAS inhibition and cardiorenal syndrome. Curr Hypertens Rev. 2014:10(2):107-11.

13. Lekawanvijit S, Kompa AR, Wang BH, Kelly DJ, Krum H. Cardiorenal syndrome: the emerging role of protein-bound uremic toxins. Circ Res. 2012;111(11):1470-83.

14. Charytan DM, Fishbane S, Malyszko J, McCullough PA, Goldsmith D. Cardiorenal syndrome and the role of the bone-mineral axis and anemia. Am J Kidney Dis. 2015;66(2):196-205.

15. Ueda S, Yamagishi S, Yokoro M, Okuda S. Role of asymmetric dimethylarginine in cardiorenal syndrome. Curr Pharm Des. 2014;20(14):2448-55.

16. Tong J, Liu M, Li H, Luo Z, Zhong X, Huang J, Liu R, He F, Fu J. Mortality and associated risk factors in dialysis patients with cardiovascular disease. Kidney Blood Press Res. 2016:41(4):479-87.

17. Nishikawa K, Takahashi K, Yamada R, Kinaga T, Masato M, Yamamoto M. Influence of chronic kidney disease on hospitalization, chronic dialysis, and mortality in Japanese men: a longitudinal analysis. Clin Exp Nephrol. 2016 [Epub ahead of print].

18. Cheung AK, Sarnak MJ, Yan G, Berkoben M, Heyka R, Kaufman A, Lewis J, Rocco M, Toto R, Windus D, Ornt D, Levey AS, HEMO Study Group. Cardiac diseases in maintenance hemodialysis patients: results of the HEMO Study. Kidney Int. 2004;65(6):2380-9.

19. Hishida M, Tamai H, Morinaga T, Maekawa M, Aoki T, Tomida H, Komatsu S, Kamiya T, Maruyama S, Matsuo S, Inaguma D. Aichi cohort study of the prognosis in patients newly initiated into dialysis (AICOPP): baseline characteristics and trends observed in diabetic nephropathy. Clin Exp Nephrol. 2016 [Epub ahead of print].

20. Kanda Y. Investigation of the freely available easy-to-use software 'EZR' for medical statistics. Bone Marrow Transplant. 2013;48(3):452-8.

21. Ng YY, Hung YN, Wu SC, Ko PJ, Hwang SM. Progression in comorbidity before hemodialysis initiation is a valuable predictor of survival in incident patients. Nephrol Dial Transplant. 2013;28(4):1005-12.

22. Gomez AT, Kiberd BA, Royston JP, Alfaadhel T, Soroka SD, Hemmelgarn BR, Tennankore KK. Comorbidity burden at dialysis initiation and mortality: a cohort study. Can J Kidney Health Dis. 2015;2:34. doi:10.1186/s40697-015-0068-3.

23. Wu PH, Lin YT, Lee TC, Lin MY, Kuo MC, Chiu YW, Hwang SJ, Chen HC. Predicting mortality of incident dialysis patients in Taiwan-a longitudinal population-based study. PLoS One. 2013;8(4):e61930. doi:10.1371/journal. pone.0061930

24. Ivory SE, Polkinghorne KR, Khandakar Y, Kasza J, Zoungas S, Steenkamp R, Roderick P, Wolfe R. Predicting 6-month mortality risk of patients commencing dialysis treatment for end-stage kidney disease. Nephrol Dial Transplant. 2017 [Epub ahead of print].

25. Ganesh SK, Hulbert-Shearon T, Port FK, Eagle K, Stack AG. Mortality differences by dialysis modality among incident ESRD patients with and without coronary artery disease. J Am Soc Nephrol. 2003;14(2):415-24.

26. JCS Joint Working Group. Guidelines for secondary prevention of myocardial infarction (JCS 2011). Circ J. 2013;77(1):231-48.

27. Joki N, Hase $H$, Nakamura $R$, Yamaguchi $T$. Onset of coronary artery disease prior to initiation of haemodialysis in patients with end-stage renal disease. Nephrol Dial Transplant. 1997;12(4):718-23.

28. Ohtake T, Kobayashi S, Moriya H, Negishi K, Okamoto K, Maesato K, Saito S. High prevalence of occult coronary artery stenosis in patients with chronic kidney disease at the initiation of renal replacement therapy: an angiographic examination. J Am Soc Nephrol. 2005;16(4):1141-8.

\section{Submit your next manuscript to BioMed Central and we will help you at every step:}

- We accept pre-submission inquiries

- Our selector tool helps you to find the most relevant journal

- We provide round the clock customer support

- Convenient online submission

- Thorough peer review

- Inclusion in PubMed and all major indexing services

- Maximum visibility for your research

Submit your manuscript at www.biomedcentral.com/submit
Biomed Central 